\title{
A comparison of quality of life in mitral valve replacement and mitral valve repair patients
}

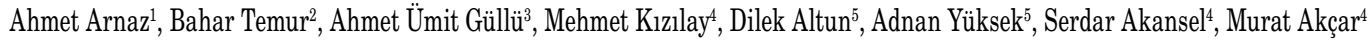 \\ ${ }^{1}$ Department of Cardiovascular Surgery, Acıbadem Bakırköy Hospital, İstanbul, Turkey \\ ${ }^{2}$ Department of Cardiovascular Surgery, Acıbadem Atakent Hospital, İstanbul, Turkey \\ ${ }^{3}$ Department of Cardiovascular Surgery, Acıbadem Maslak Hospital, İstanbul, Turkey \\ ${ }^{4}$ Department of Cardiovascular Surgery, Dr. Siyami Ersek Thoracic and Cardiovascular Surgery Training and Research Hospital, İstanbul, Turkey \\ ${ }^{5}$ Department of Anesthesiology and Reanimation, Acıbadem Bakırköy Hospital, İstanbul, Turkey
}

Received: October 06, 2016 Accepted: January 02, 2017 Published online: April 17, 2017

\section{ABSTRACT}

Objectives: Mitral valve replacement and repair are the surgical treatment methods in mitral valve disease. Although both treatments have some superiorities against each other in some certain fields, their effects on the improvement of the quality of life of patients is another factor that needs to be taken into consideration. In this study, we aimed to investigate the effects of these treatment methods on the improvement of the quality of life.

Patients and methods: Between January 2006 and June 2009, a total of 40 patients ( 27 females, 13 males; mean age $48.2 \pm 14.8$ years; range 16 to 74 years) with similar etiologies and EuroSCORE values were included in this prospective, single-center study. All patients were divided into two groups as mitral valve replacement (group 1, $n=22$ ) and mitral valve repair (group 2, n=18). The Short Form-36 was used to assess the improvement in the quality of life.

Results: Seven of eight domains including physical function, role limitation due to physical function, social function, role limitation due to emotional problems, energy, mental health, and general health perception in the Short Form-36 were significantly improved in both groups. Pain scores were significantly improved in group 2, whereas no significant improvement was seen in group 1.

Conclusion: Our study results show a significant improvement in the quality of life following both treatments. However, mitral valve repair seems to be superior to mitral valve replacement in terms of pain scores.

Keywords: Mitral valve repair; mitral valve replacement; quality of life.

Mitral valve diseases are very common in both developed and developing countries and considerably affect mortality and morbidity. ${ }^{[1-5]}$ The optimal timing for the surgical treatment of valve disease is before the permanent myocardial damage and serious symptoms occur. ${ }^{[6]}$ Mitral valve diseases include both mitral valve stenosis and regurgitation. In addition, structural valve disease became surgically treatable after the introduction of the cardiopulmonary bypass system. Replacement of the damaged valve was the first choice in surgical treatment, since it is easier to perform and the results are more predictable. However, mitral valve repair $(\mathrm{MVr})$ has become more popular, since mitral valve replacement (MVR) is associated with a high risk of thromboembolism, endocarditis, and left ventricular dysfunction. ${ }^{[7-9]}$ Furthermore, it is necessary to use anticoagulants after MVR. In addition, $\mathrm{MVr}$ has a lower risk of thromboembolism and valvular infections, and requires less reoperation. ${ }^{[10]}$ It is more popular thanks to these advantages. ${ }^{[10,11]}$ On the other hand, although repair is more popular today, MVR still has more advantages in certain conditions. Mitral valve replacement is in favor in patients with ischemic valvular disease, as MVr takes more time and, therefore, the duration of cardiopulmonary bypass machine use is longer. ${ }^{[12]}$ Furthermore, MVr needs a great knowledge about the mitral valve morphology and structure, and an adequate experience. Nonetheless, previous studies have shown no significant difference between MVR and $\mathrm{MVr}$ in terms of long-time survival and mortality rates in patients with ischemic mitral valve disease. ${ }^{[13,14]}$

Although there are some new advanced biomaterials designed for valve production, they are still far from being the ideal materials. Neither mechanical nor biological valves are as ideal, as the patient's own valve. Although biological valves function much

Corresponding author: Ahmet Arnaz, M.D. Acıbadem Bakırköy Hastanesi Kalp ve Damar Cerrahisi Kliniği, 34140 Bakırköy, İstanbul, Turkey.

Tel: +90 532 - 2753944 e-mail: ahmetarnaz@yahoo.com 
more like the natural valve of the human heart, they still tend to become deteriorated and need a replacement in a shorter time of period, compared to the mechanical valves. ${ }^{[15]}$ Therefore, we can suggest that there is no prosthetic valve which provides an excellent hemodynamic properties without causing early and late mortality risks and not easy to supply and cannot be used by all surgeons. ${ }^{[16]}$ Both of these two techniques have some superiority against each other. The primary goal is to heal the disease and to protect the functional capacity in the treatment of the patients with mitral valve disease. Therefore, one of the major outcomes of the treatment is to improve the quality of life (QoL) in these patients.

In the present study, we aimed to investigate the effects of MVR and MVr on the improvements in the QoL.

\section{PATIENTS AND METHODS}

A total of 40 patients ( 27 females, 13 males; mean age $48.2 \pm 14.8$ years; range 16 to 74 years) who underwent MVR and MVr at Dr. Siyami Ersek Thoracic and Cardiovascular Training and Research Hospital, Istanbul, Turkey between January 2006 and June 2009 were included in this prospective, single-center study. All patients had a similar etiology, diagnosis, and EuroSCORE values. The Short Form-36 (SF-36), which is a questionnaire with 36 questions concerning the QoL and health care, was used to assess QoL of the patients at baseline and at six months of surgery. Face-to-face interview method was used to make sure that the patient fully understood the questions in the SF-36 scale. All patients were divided into two groups as group $1(\mathrm{MVR}, \mathrm{n}=22)$ and group 2 $(\mathrm{MVr}, \mathrm{n}=18)$. The patients who underwent only mitral and tricuspid valve interventions were included, and those who underwent double valve replacement or additional procedures (coronary artery bypass grafting or ascending aorta aneurysm repair) were excluded. Data including age and gender, diabetes mellitus, tobacco use, hypertension, cerebrovascular stroke, renal insufficiency, EuroSCORE, and myocardial infarction were recorded. Following parameters were investigated in the preoperative echocardiograms: stenosis (pure stenosis, predominant stenosis, predominant insufficiency, pure insufficiency) and diastolic diameter of the left ventricle, ejection fraction (EF), left atrium diameter, and mean pulmonary artery pressure. Cross-clamp and cardiopulmonary bypass times were also recorded. The mean body surface area was calculated.

The study was approved by the local Ethics Committee and conducted in accordance with the principles of the Declaration of Helsinki.

\section{Surgical technique}

A written informed consent was obtained from each patient. All operations were performed by three different surgical teams at a single-center, using the same surgical principles. Median sternotomy was used in both groups. Right atriotomy and transseptal incision were performed in tricuspid annuloplasty patients. The mitral valve was reached via only the left atriotomy in patients who were treated for only mitral valve dysfunction. The valve was excised and Teflon-pledged sutures (2.0 polyester, Ethicon Inc., Somerville, NJ, USA) were used to implant the mitral valve. Different techniques were used to repair the mitral valve such as commissurotomy, quadrangular resection, and sliding annuloplasty, posterior annuloplasty, and cleft repair.

\section{Statistical analysis}

Statistical analysis was performed using the Number Cruncher Statistical System (NCSS, LLC, Kaysville, Utah, USA). Descriptive data were expressed in mean + standard deviation. The Student's t-test was used to compare normally distributed variables, while the Mann-Whitney $U$ test was used to compare abnormally distributed variables between the two groups. The Wilcoxon sign test was used to analayze intra-group variables. The Fisher's exact and FisherFreeman-Halton tests were carried out to compare qualitative data. A $p$ value of $<0.05$ was considered statistically significant.

\section{RESULTS}

A total of 22 patients underwent MVR, while 18 patients underwent $\mathrm{MVr}$. None of the patients died after the operation until sixth month of the postoperative period. Baseline EF was $55.86 \%$ and 60.28\%, while baseline EuroSCORE was 2.5 and 2.78 in group 1 and group 2, respectively (Table 1). Mitral valve disease had rheumatic and degenerative etiology in 29 and 11 patients, respectively. Thirty patients were classified as the New York Heart Association (NYHA) Class II, while the remaining 10 patients were classified as the NYHA III. There was no 


\begin{tabular}{|c|c|c|c|}
\hline Baseline ech & $\begin{array}{l}\text { e } 1 \\
\text { ings and } \mathrm{Eu}\end{array}$ & $\mathrm{RE}$ values & \\
\hline & Group 1 & Group 2 & \\
\hline & Mean \pm SD & Mean \pm SD & $p$ \\
\hline Ejection fraction, mean (\%) & $55.9 \pm 8.6$ & $60.3 \pm 5.0$ & 0.049 \\
\hline Pulmonary pressure & $41.1 \pm 10.6$ & $39.3 \pm 12.3$ & 0.619 \\
\hline Left atrium size $(\mathrm{mm})$ & $48.6 \pm 7.6$ & $43.9 \pm 9.4$ & 0.085 \\
\hline EuroSCORE & $2.5 \pm 2.2$ & $2.8 \pm 2.2$ & 0.693 \\
\hline
\end{tabular}

statistically significant difference in age, gender, mean body surface area, cardiopulmonary bypass and crossclamp time, pulmonary artery pressure, left atrial volume, EuroSCORE, etiology, NYHA classification, left ventricular internal dimension in systole (LVIDs) enlargement, cerebrovascular disease, myocardial infarction, revision and hypertension between the groups.

When the preoperative findings were evaluated, EF and tobacco use were found to be significantly higher in group $2(\mathrm{p}<0.05)$. Although a higher Class III NHYA classification was found in group 2, it was not statistically significant $(p>0.05)$. Severe heart failure

\begin{tabular}{|c|c|c|c|c|}
\hline \multicolumn{5}{|c|}{ Details of the mitral valve disease according to study groups } \\
\hline & \multicolumn{2}{|c|}{ Group 1} & \multicolumn{2}{|c|}{ Group 2} \\
\hline & $\mathrm{n}$ & $\%$ & $\mathrm{n}$ & $\%$ \\
\hline \multicolumn{5}{|l|}{ Diagnosis } \\
\hline MVF-moderate & 3 & 13.6 & 10 & 55.6 \\
\hline MVF-severe & 8 & 36.4 & 2 & 11.1 \\
\hline MS-moderate & 5 & 22.7 & 4 & 22.2 \\
\hline MS-severe & 3 & 13.6 & 1 & 5.6 \\
\hline $\mathrm{MVF}+\mathrm{MS}$ & 3 & 13.6 & 1 & 5.6 \\
\hline \multicolumn{5}{|l|}{ Etiology } \\
\hline Rheumatic & 18 & 81.8 & 11 & 61.1 \\
\hline Degenerative & 4 & 18.2 & 7 & 38.9 \\
\hline \multicolumn{5}{|l|}{ NYHA Class } \\
\hline II & 19 & 86.4 & 11 & 61.1 \\
\hline III & 3 & 13.6 & 7 & 38.9 \\
\hline \multicolumn{5}{|l|}{ Cardiac rhythm } \\
\hline Atrial fibrillation & 9 & 40.9 & 3 & 13.6 \\
\hline Sinus & 13 & 59.1 & 15 & 83.3 \\
\hline \multicolumn{5}{|l|}{ LVIDs } \\
\hline Increased & 3 & 13.6 & 0 & 0 \\
\hline Normal & 19 & 86.4 & 18 & 81.8 \\
\hline
\end{tabular}

was found to be higher in group 1, although it did not reach statistical significance ( $p>0.05)$. Baseline rhythm was atrial fibrillation in nine patients in group 1 and three patients in group 2 (Table 2).

In addition, seven of eight domains of the SF-36 including physical function, role limitation due to physical function, social function, role limitation due to emotional problems, energy, mental health, and general health perception were significantly improved after the treatment in both groups $(\mathrm{p}<0.05)$. The increases in these domains were also similar in both groups $(\mathrm{p}>0.05)$ (Table 3$)$.

There was no significant increase in terms of pain scores in group 1 ( $p>0.05)$, although pain scores significantly increased in group $2(p<0.01)$. The increase was not significantly different between two groups $(p>0.05)$. There was a significant increase in terms of general health perception scores and energy in both groups $(\mathrm{p}<0.01)$, while the increase was similar in both groups $(p>0.05)$. The social function scores increased in both group $1(\mathrm{p}<0.05)$ and group $2(\mathrm{p}<0.1)$, although the increase was statistically significant in group 2 only. However, there was no significant difference in the social function scores between the two groups.

\section{DISCUSSION}

Chronical mitral valve disease is related with significant mortality and morbidity. ${ }^{[17,18]}$ Thus, one of the primary goals of MVR or MVr is to reduce the mortality and morbidity rates. Although both methods have some superiority to each other, there are no strict rules about the order of the method that needs to be selected in a specific type of the disease. In this study, we investigated the effects of both treatment on the QoL of the patients using the SF-36 scale. 


\begin{tabular}{|c|c|c|c|c|c|}
\hline \multicolumn{6}{|c|}{$\begin{array}{c}\text { Table } 3 \\
\text { Results of the Short Form-36 scale }\end{array}$} \\
\hline & \multicolumn{2}{|c|}{ Group 1} & \multicolumn{2}{|c|}{ Group 2} & \multirow[b]{2}{*}{$p$} \\
\hline & Mean \pm SD & Median & Mean \pm SD & Median & \\
\hline \multicolumn{6}{|l|}{ Physical function } \\
\hline Preoperative & $45.5 \pm 25.4$ & 40 & $34.2 \pm 27.4$ & 22.5 & 0.127 \\
\hline Postoperative & $81.1 \pm 13.8$ & 80 & $75.0 \pm 27.3$ & 82.5 & 0.901 \\
\hline$p$ & \multicolumn{2}{|c|}{0.001} & \multicolumn{2}{|c|}{0.001} & \\
\hline \multicolumn{6}{|c|}{ Role limitation due to physical function } \\
\hline Preoperative & $22.7 \pm 40.8$ & 0 & $15.3 \pm 35.5$ & 0 & 0.445 \\
\hline Postoperative & $78.4 \pm 38.8$ & 100 & $72.2 \pm 41.9$ & 100 & 0.844 \\
\hline$p$ & \multirow{2}{*}{\multicolumn{2}{|c|}{0.002}} & \multicolumn{2}{|c|}{0.001} & \\
\hline \multicolumn{5}{|l|}{ Pain } & \\
\hline Preoperative & $65.5 \pm 29.7$ & 68 & $61.6 \pm 25.7$ & 58 & 0.528 \\
\hline Postoperative & $75.9 \pm 24.9$ & 84 & $82.9 \pm 14.4$ & 79 & 0.556 \\
\hline$p$ & \multicolumn{2}{|c|}{0.102} & \multicolumn{2}{|c|}{0.005} & \\
\hline \multicolumn{6}{|c|}{ General health perception } \\
\hline Preoperative & $34.0 \pm 22.6$ & 27.5 & $29.6 \pm 25.3$ & 23.5 & 0.414 \\
\hline Postoperative & $70.0 \pm 16.5$ & 72.0 & $65.3 \pm 23.8$ & 68.5 & 0.614 \\
\hline$p$ & \multicolumn{2}{|c|}{0.001} & \multicolumn{2}{|c|}{0.001} & \\
\hline \multicolumn{6}{|l|}{ Energy } \\
\hline Preoperative & $33.9 \pm 22.1$ & 32.5 & $34.4 \pm 18.4$ & 35 & 0.712 \\
\hline Postoperative & $63.2 \pm 16.2$ & 65 & $67.2 \pm 22.9$ & 72.5 & 0.223 \\
\hline \multirow{2}{*}{\multicolumn{6}{|c|}{ Social function }} \\
\hline & & & & & \\
\hline Preoperative & $55.7 \pm 22.4$ & 50 & $41.7 \pm 27.5$ & 37.5 & 0.063 \\
\hline Postoperative & $74.4 \pm 17.9$ & 75 & $77.1 \pm 26.2$ & 87.5 & 0.402 \\
\hline \multirow{2}{*}{\multicolumn{6}{|c|}{ Role limitation due to emotional problems }} \\
\hline & & & & & \\
\hline Preoperative & $42.4 \pm 25.6$ & 33.3 & $35.2 \pm 31.3$ & 33.33 & 0.302 \\
\hline Postoperative & $68.2 \pm 30.0$ & 66.67 & $57.4 \pm 33.9$ & 66.67 & 0.294 \\
\hline \multirow{2}{*}{\multicolumn{6}{|c|}{$\begin{array}{l}\text { P } \\
\text { Mental health }\end{array}$}} \\
\hline & & & & & \\
\hline Preoperative & $48.4 \pm 18.9$ & 44 & $50.7 \pm 17.7$ & 50 & 0.540 \\
\hline Postoperative & $70.7 \pm 17.5$ & 74 & $72.2 \pm 21.7$ & 76 & 0.567 \\
\hline$p$ & \multicolumn{2}{|c|}{0.001} & \multicolumn{2}{|c|}{0.001} & \\
\hline
\end{tabular}

It is not always possible to prevent mitral valve regurgitation after MVr. Soon or later, regurgitation is expected to recur. In the presence of a significant level of calcification or fibrosis, it is reasonable to perform a MVR operation to decrease the need for reoperation. In a recent meta-analysis, MVR and repair were compared in terms of multiple factors and it was found that $\mathrm{MVr}$ was related to an increased reoperation risk in patients with progressive rheumatic mitral valve disease. ${ }^{[19]}$ It was also reported that there was no significant difference between MVR and
$\mathrm{MVr}$ in terms of the survival rates in patients with ischemic mitral valve disease. ${ }^{[20-22]}$ However, 30 days of mortality reduced in patients who underwent MVr. In another study, MVr was found to be related to a longer survival, and valve replacement was a risk factor in terms of long-term mortality. ${ }^{[23]}$ Based on our findings, we can conclude that the method to be chosen for patients with mitral valve disease needs a multi-factorial assessment including age, etiology, comorbidities, additional cardiac pathologies, and severity of the mitral valve disease. Previous studies 
also showed that $\mathrm{MVr}$ was related with a lower incidence of in-hospital mortality, longer survival, increased left ventricle functions, and a lower risk of valve-related complications. ${ }^{[24-26]}$ Accordingly, $\mathrm{MVr}$ is more popular, particularly in patients in whom the ventricular function should be preserved carefully. ${ }^{[27,28]}$ The primary goal of mitral valve operation is to heal the disease, while protecting the functional capacity. Of note, the main goal of all treatment modalities should be to improve the $\mathrm{QoL}$ of patients.

Furthermore, we found significantly improved pain scores in group $2(\mathrm{p}<0.01)$, while no statistically significant improvement was seen in group $1(p>0.05)$. This finding is also consistent with the finding in a previous study. ${ }^{[29]}$ In the aforementioned study, however, Goldsmith and Pate ${ }^{[29]}$ compared preoperative SF-36 results with third-month results. In another study, prognosis was reported to be poor in patients with an $\mathrm{EF}<50 \%$ and left ventricle dysfunction. ${ }^{[6]}$ In addition, Goldsmith and Patel ${ }^{[29]}$ found no significant improvement in the QoL of the patients with an EF value lower than $50 \%$. Our study included only three patients with an $\mathrm{EF}$ value lower than $50 \%$, and a significant improvement was seen in the QoL of these three patients.

The major limitations of the present study include being a single-center study, performing all operations by three different surgical teams, a small sample size, and not having mechanical and biological valve replacements in two different groups.

In conclusion, our study results show a significant improvement in the quality of life following both treatments. However, mitral valve repair seems to be superior to mitral valve replacement in terms of pain scores.

\section{Declaration of conflicting interests}

The authors declared no conflicts of interest with respect to the authorship and/or publication of this article.

\section{Funding}

The authors received no financial support for the research and/or authorship of this article.

\section{REFERENCES}

1. Iung B, Baron G, Butchart EG, Delahaye F, Gohlke-Bärwolf $\mathrm{C}$, Levang OW, et al. A prospective survey of patients with valvular heart disease in Europe: The Euro Heart Survey on Valvular Heart Disease. Eur Heart J 2003;24:1231-43.
2. Nkomo VT, Gardin JM, Skelton TN, Gottdiener JS, Scott CG, Enriquez-Sarano M. Burden of valvular heart diseases: a population-based study. Lancet 2006;368:1005-11.

3. Patel JB1 Borgeson DD, Barnes ME, Rihal CS, Daly RC, Redfield MM. Mitral regurgitation in patients with advanced systolic heart failure. J Card Fail 2004;10:285-91.

4. Rossi A, Dini FL, Faggiano P, Agricola E, Cicoira M, Frattini $S$, et al. Independent prognostic value of functional mitral regurgitation in patients with heart failure. A quantitative analysis of 1256 patients with ischaemic and non-ischaemic dilated cardiomyopathy. Heart 2011;97:1675-80.

5. Trichon BH, Felker GM, Shaw LK, Cabell CH, O'Connor CM. Relation of frequency and severity of mitral regurgitation to survival among patients with left ventricular systolic dysfunction and heart failure. Am J Cardiol 2003;91:538-43.

6. Enriquez-Sarano M, Tajik AJ, Schaff HV, Orszulak TA, Bailey KR, Frye RL. Echocardiographic prediction of survival after surgical correction of organic mitral regurgitation. Circulation 1994;90:830-7.

7. Detaint D, Sundt TM, Nkomo VT, Scott CG, Tajik AJ, Schaff $\mathrm{HV}$, et al. Surgical correction of mitral regurgitation in the elderly: outcomes and recent improvements. Circulation 2006;114:265-72.

8. Ling LH, Enriquez-Sarano M, Seward JB, Orszulak TA, Schaff HV, Bailey KR, et al. Early surgery in patients with mitral regurgitation due to flail leaflets: a long-term outcome study. Circulation 1997;96:1819-25.

9. Yun KL, Miller DC. Mitral valve repair versus replacement. Cardiol Clin 1991;9:315-27.

10. Sarris GE, Cahill PD, Hansen DE, Derby GC, Miller DC. Restoration of left ventricular systolic performance after reattachment of the mitral chordae tendineae. The importance of valvular-ventricular interaction. J Thorac Cardiovasc Surg 1988;95:969-79.

11. Okita Y, Miki S, Ueda Y, Tahata T, Sakai T, Matsuyama K. Comparative evaluation of left ventricular performance after mitral valve repair or valve replacement with or without chordal preservation. J Heart Valve Dis 1993;2:159-66.

12. Kim YH, Czer LS, Soukiasian HJ, De Robertis M, Magliato $\mathrm{KE}$, Blanche $\mathrm{C}$, et al. Ischemic mitral regurgitation: revascularization alone versus revascularization and mitral valve repair. Ann Thorac Surg 2005;79:1895-901.

13. Enriquez-Sarano M, Schaff HV, Frye RL. Mitral regurgitation: what causes the leakage is fundamental to the outcome of valve repair. Circulation 2003;108:253-6.

14. Harris KM, Sundt TM, Aeppli D, Sharma R, Barzilai B. Can late survival of patients with moderate ischemic mitral regurgitation be impacted by intervention on the valve? Ann Thorac Surg 2002;74:1468-75.

15. Galloway AC, Colvin SB, Baumann FG, Harty S, Spencer FC. Current concepts of mitral valve reconstruction for mitral insufficiency. Circulation 1988;78:1087-98.

16. Edmunds LH Jr. Thrombotic and bleeding complications of prosthetic heart valves. Ann Thorac Surg 1987;44:430-45.

17. Avierinos JF, Gersh BJ, Melton LJ, Bailey KR, Shub C, Nishimura RA, et al. Natural history of asymptomatic mitral valve prolapse in the community. Circulation 
2002;106:1355-61.

18. Ling LH, Enriquez-Sarano M, Seward JB, Tajik AJ, Schaff $\mathrm{HV}$, Bailey KR, et al. Clinical outcome of mitral regurgitation due to flail leaflet. N Engl J Med 1996;335:1417-23.

19. Shuhaiber J, Anderson RJ. Meta-analysis of clinical outcomes following surgical mitral valve repair or replacement. Eur J Cardiothorac Surg 2007;31:267-75.

20. Calafiore AM, Di Mauro M, Gallina S, Di Giammarco $G$, Iacò $A L$, Teodori $G$, et al. Mitral valve surgery for chronic ischemic mitral regurgitation. Ann Thorac Surg 2004;77:1989-97.

21. Cohn LH, Rizzo RJ, Adams DH, Couper GS, Sullivan TE, Collins JJ Jr, et al. The effect of pathophysiology on the surgical treatment of ischemic mitral regurgitation: operative and late risks of repair versus replacement. Eur J Cardiothorac Surg 1995;9:568-74.

22. Grossi EA, Goldberg JD, LaPietra A, Ye X, Zakow P, Sussman $\mathrm{M}$, et al. Ischemic mitral valve reconstruction and replacement: comparison of long-term survival and complications. J Thorac Cardiovasc Surg 2001;122:1107-24.

23. Sand ME, Naftel DC, Blackstone EH, Kirklin JW, Karp RB. A comparison of repair and replacement for mitral valve incompetence. J Thorac Cardiovasc Surg1987;94:208-19.

24. Gillinov AM, Cosgrove DM, Blackstone EH, Diaz R,
Arnold JH, Lytle BW, et al. Durability of mitral valve repair for degenerative disease. J Thorac Cardiovasc Surg 1998;116:734-43.

25. Suri RM, Schaff HV, Dearani JA, Sundt TM, Daly RC, Mullany CJ, et al. Survival advantage and improved durability of mitral repair for leaflet prolapse subsets in the current era. Ann Thorac Surg 2006;82:819-26.

26. Tribouilloy CM, Enriquez-Sarano M, Schaff HV, Orszulak TA, Bailey KR, Tajik AJ, et al. Impact of preoperative symptoms on survival after surgical correction of organic mitral regurgitation: rationale for optimizing surgical indications. Circulation 1999;99:400-5.

27. Barnett SD, Ad N. Surgery for aortic and mitral valve disease in the United States: a trend of change in surgical practice between 1998 and 2005. J Thorac Cardiovasc Surg 2009;137:1422-9.

28. Gammie JS, Sheng S, Griffith BP, Peterson ED, Rankin JS, O'Brien SM, et al. Trends in mitral valve surgery in the United States: results from the Society of Thoracic Surgeons Adult Cardiac Surgery Database. Ann Thorac Surg 2009;87:1431-7.

29. Goldsmith IR, Lip GY, Patel RL. A prospective study of changes in the quality of life of patients following mitral valve repair and replacement. Eur J Cardiothorac Surg 2001;20:949-55. 